\title{
From tennis balls to pearls: Bridging the communication gap to surgical trainees
}

\author{
Scott I. Reznik, MD
}

\footnotetext{
From the Department of Cardiovascular and Thoracic Surgery, University of Texas Southwestern Medical Center, Dallas, Tex.

Disclosures: Author has nothing to disclose with regard to commercial support.

Received for publication April 30, 2017; accepted for publication May 8, 2017; available ahead of print July 1, 2017.

Address for reprints: Scott I. Reznik, MD, Department of Cardiovascular and Thoracic Surgery, University of Texas Southwestern Medical Center, 5323 Harry Hines Blvd, MC8879, Dallas, TX 75390-8879 (E-mail: Scott.reznik@utsouthwestern.edu).

J Thorac Cardiovasc Surg 2017;154:1013-4

$0022-5223 / \$ 36.00$

Copyright (c) 2017 by The American Association for Thoracic Surgery

http://dx.doi.org/10.1016/j.jtcvs.2017.05.017
}

Dr Ibrahimiye's essay “How Andre Agassi Helped Me During My Cardiothoracic Surgery Training," in this issue of the Journal, shares some of the pearls he has acquired through his recent training in cardiothoracic and congenital heart surgery. Surgical training is rife with land mines, aphorisms, and well-meaning advice. As surgical educators, we hope our trainees listen to our advice that may contradict our actions or be ignored as the ramblings of an elder talking about the good old days. Perhaps we are not speaking the same language.

The surest way to make a resident's eyes roll is to begin with, "When I was a resident..." and regale the trainees with stories of continuous call, never leaving the bedside, and loving every minute of it. The prism through which we recall our training tends to distort the facts. To compound the problem, training paradigms and the practice of cardiothoracic surgery have changed significantly. Multiple redo operations were rare, routine coronary bypasses were common, and public reporting was a new idea. Bridging the cultural and generational communication gap with our residents may improve the efficacy of the message.

Although the operating room is the raison d'être of surgical training, we all tell our residents to read more, practice more, and go to the clinic occasionally instead of the operating room. These pleas often fall on deaf ears. It brings both happiness and schadenfreude, when a former resident, recently in practice, tells me, "You were right; I wish had gone to clinic more, or learned more about those studies, etc." I always respond with a smile and ask them if they would share this with the current residents. With Dr Ibrahimiye's essay, we now have that opportunity for a relatively newly minted surgeon to share these pearls with his colleagues without having to cross the generational divide. One principle of adult education is to begin teaching a subject by activating prior knowledge. Even though not everyone has read Open, ${ }^{2}$ most readers have enough familiarity with tennis to understand the analogy. More important, as a recent resident, Dr Ibrahimiye still has the

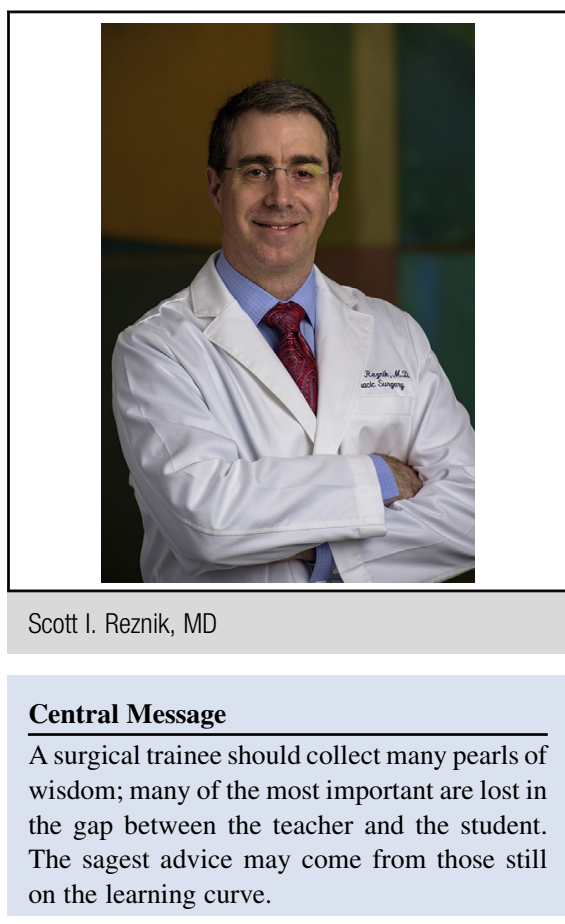

See Article page 1008 .

credibility to make trainees believe him. He builds from the perspective of a resident.

Many educational experts believe there are 4 stages in learning:

1. Unconsciously incompetent (you do not know what you do not know)

2. Consciously incompetent (you know that you do not know)

3. Consciously competent (you know that you know)

4. Unconsciously competent (you do not know that you know) $)^{3}$

Most trainees transition from levels 2 to 3 . Level 3 learners can perform tasks, but it requires conscious thought. ${ }^{4}$ Level 3 practitioners are often better at teaching lower-level learners precisely because they are consciously thinking through the process and often better at articulating it than the level 4 expert who unconsciously knows. As a recent graduate, Dr Ibrahimiye may have retained his consciousness. There are many pearls in Dr Ibrahimiye's essay. Not every pearl will fit every trainee, but readers can glean different pearls from each reading. 


\section{References}

1. Ibrahimiye AN. How Andre Agassi helped me during my cardiothoracic surgery training. J Thorac Cardiovasc Surg. 2017;154:1008-12.

2. Agassi A. Open: An Autobiography. 1st ed. New York: A. Knopf; 2009.
3. Peyton JWR. Teaching \& Learning in Medical Practice. Hertfordshire, England: Heronsgate Rickmansworth, Herts: Manticore Europe Ltd; 1998.

4. Lake FR, Hamdorf JM. Teaching on the run tips 5: teaching a skill. Med J Aust. 2004;181:327-8. 